\title{
Current challenges in the therapeutic use of induced pluripotent stem cells (iPSCs) in cancer therapy
}

\author{
Pravin Potdar ${ }^{*}$ and Shahid Chaudhary
}

\begin{abstract}
Induced Pluripotent Stem Cells (iPSCs) technology has catapulted the field of stem-cell biology through ectopic expression of reprogramming factors. Ever since its discovery, the potential of iPSCs has been explored by many scientists to unravel the molecular mechanism responsible for cancer initiation and progression. Besides modeling cancer, the further applications of this technology includes high-throughput drug screening, epigenetic reprogramming of cancer cell state to normal, immunotherapy and regenerative cell therapies. Here, we review the current challenges on clinical applications of iPSCs with respect to understanding cancer and personalizing treatment for the disease.
\end{abstract}

Keywords: iPSCs, Stem Cells, Reprogramming, Cancer Therapy, Pluripotency genes

\section{Background}

\section{Brief history of pluripotency}

Reprogramming somatic cells has a long history back in the year 1966 when adult frog was developed by nuclear transplantation of differentiated somatic cell nuclei. Initially, this finding was heavily criticized but got validated later and generated many speculations regarding the totipotency nature of differentiated adult nuclei [1]. After success of nuclear transfer technology in frog, various animal models including sheep which has resulted in the generation of Dolly from cells derived from the adult mammary glands [2]. The birth of viable lamb has reinforced the previous speculations that the molecular clock of differentiated cells can be reverse back to the embryonic stage and they still retain the epigenetic memory of embryonic development. However, cloning suffered a number of disadvantages because of the inefficiency of technique and the dangerous impact it has on the individual clones. The discovery of human embryonic stem cells (hESCs) in the year 1998 has revolutionized the field of stem cells and regenerative medicine because of the remarkable potential of hESCs to differentiate into any cell types of the body [3]. Nevertheless, the use of hESCs poses many ethical and immunogenic issues.

\footnotetext{
*Correspondence: ppotdar@jaslokhospital.net; ppravin012@gmail.com; http://www.jaslokhospital.net

Department of Molecular Medicine and Biology, Jaslok Hospital \& Research Centre, 15 Dr. G. DeshmukhMarg, Mumbai 400026, Maharashtra, India
}

These limitations were overcome in 2006 when Takashaki and Yamanaka reported the reprogramming of murine fibroblast by ectopic expression of Oct4, Sox2, Klf4 and c-Myc [4]. Similar finding was translated to human dermal fibroblasts by two independent research group in 2007 $[5,6]$. These cells referred to as induced pluripotent stem cells (iPSCs) exhibit similar morphological, proliferative, genomic and phenotypic characteristics as hESCs as well as express analogous cell surface antigens.

Ever since the discovery of iPSCs, it has ushered a new era of personalizing pluripotency genes excluding the involvement of ethical concern while simultaneously addressing the issue of transplantation without the fear of graft rejection. Scientists have started to generate patient-specific iPSCs to unravel the molecular mechanism responsible for Fanconi anemia [7], diabetes [8] and Wilson's disease [9]. The only drawback of this technology for its use in personalized medicine is the risk associated with the use of lentiviral or retroviral vectors resulting in genomic integration and insertion mutagenesis [10]. In addition, generation of iPSCs is limited due to lower reprogramming efficiency [1] and the longer duration it takes for reprogramming (several weeks) [11]. To overcome viral vector mediated genotoxicity, reprogramming methods have been refined progressively to deliver programming factors either by using non-integrating viruses $[12,13]$, episomal vectors [14] and direct delivery of 
mRNA molecules [15]. In addition, small molecules such as valproic acid have been substituted for the oncogene c-Myc and it has been shown to increase the reprogramming efficiency by 100 -fold [16]. Another approach to improve reprogramming efficiency is by expressing cofactors such as $\mathrm{BAF}(\mathrm{Brg} 1 / \mathrm{Brm}$ associated factor)- complex that modulates the de-methylation status of pluripotency gene promoters $[17,18]$. However, in spite of all the efforts towards increasing the reprogramming efficiency there is still a deficit in establishing the optimal reprogramming protocol.

\section{How iPSCs can help to cure cancer?}

Even though we are living in the post-genomic era, there are still many questions in the field of cancer biology that need to be answered. The foremost question is what makes a cancer cell a cancer cell? Are we even closer to eradicate cancer completely? Treating cancer is still one of the most daunting tasks of $21^{\text {st }}$ century despite of all the scientific advances in cancer treatment over the past 30 years. Out of all the types, metastatic cancer remain the most challenging one as there are very few therapeutic options and majority of the patient show severe side-effects resulting in mortality because of the treatment itself. But how can the potential of iPSCs be harness to treat cancer patients? There are four possible scenarios where iPSCs might be of value as shown in Fig. 1: i) modeling cancer pathogenesis \& drug screening ii) reprogramming cancer cells back to normal phenotype iii) cancer immunotherapy iv) regenerative cell therapies.

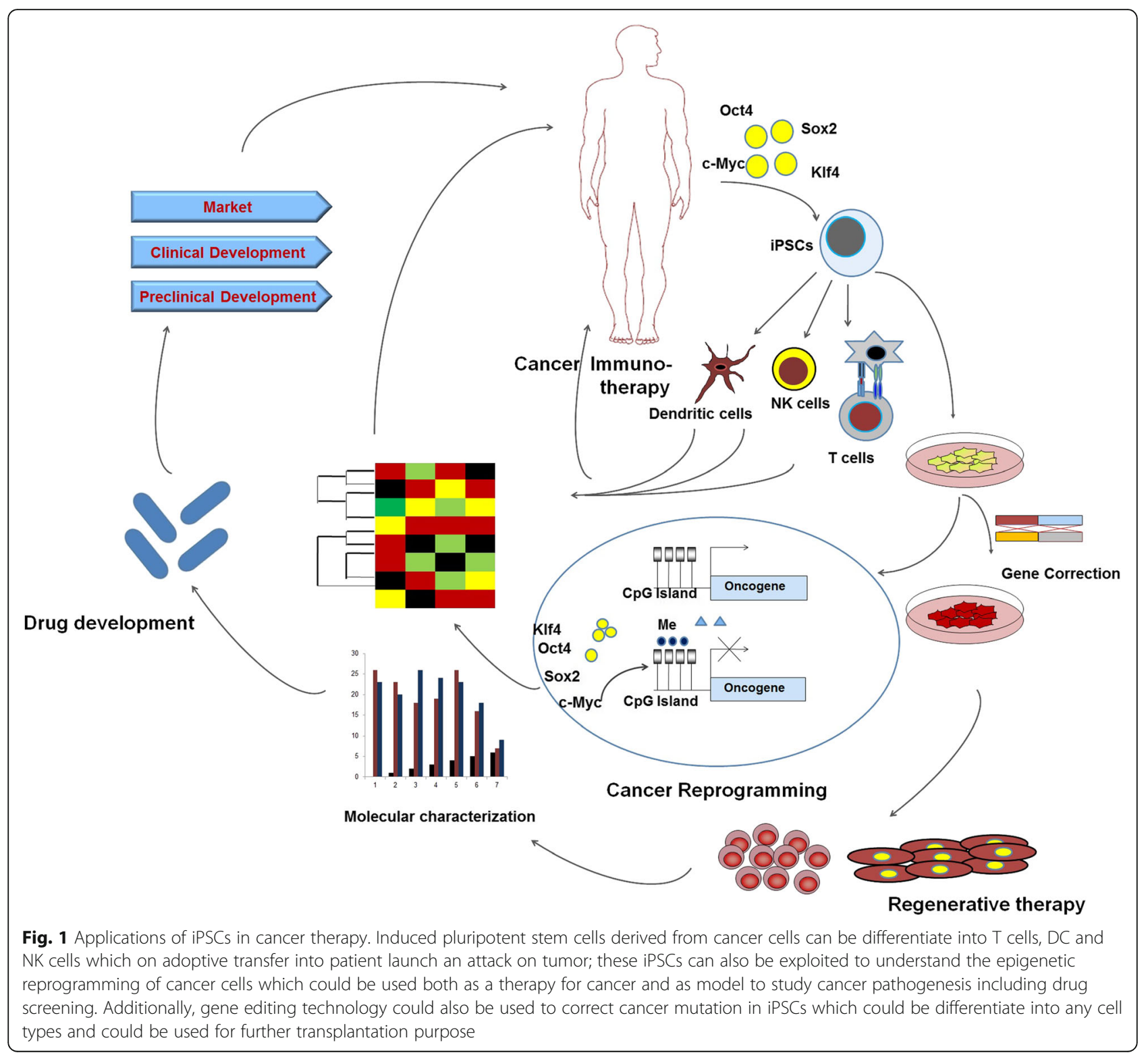




\section{Modeling cancer pathogenesis and drug screening using cancer-specific iPSCs}

The molecular mechanism responsible for malignant transformation is still not clearly understood to many scientists and conducting such analysis in patient samples does not represent a perfect model because the transformation event has already occurred when cancers are studied. Therefore, there is a big lag in data to unravel the early stages of cancer progression because of the inadequate system to recapitulate the cancer phenotype. Moreover cancer-specific mutations, deletions, translocations are usually associated to particular tissue type which indicates that the effect of these mutations are not only influenced by the environmental triggers but also heavily dictated by the epigenetic states of a cell [19] Therefore, iPSCs provide a platform to understand the association of oncogenic mutations with different tissue types and how these mutations dictate the malignant fate of the cell.

For instance, pancreatic ductal adenocarcinoma (PDAC)derived iPSCs demonstrate the in vitro model system to develop pancreatic intraepithelial neoplasia which can further progressed to pancreatic cancer. By using immunodeficient mice, Kim's group has shown that PDAC-derived iPSCs when injected into the mice, they generated progenitors of PDAC referred to as pancreatic intraepithelial neoplasia (PanIN). This PanIN later progress to the metastatic stage and further profiling of PanIN reveals the network of many proteins centered on the gene HNF4a. This gene was not previously implicated in PDAC and therefore provides new insights into pancreatic cancer progression [20]. Thus, iPSCs proves to be a valuable tool in capturing the early stage of cancer progression. Li Fraumeni syndrome (LFS) which is caused due to the mutation in the p53 gene has been successfully modeled by using iPSCs technology [21]. Initially it was difficult to understand the molecular pathogenesis of this disease because LFS patients suffers from wide spectrum of cancers and the mouse model of LFS could only provide the one-dimensional information on the disease. LFS patient-derived iPSCs recapitulated all the hallmarks of the disease and thus establishing as a stand-alone model system for familial cancer covering all the extreme ends of cancer spectrum.

In addition, large-throughput drug screening and development can be assayed by reprogramming cancer-cellspecific iPSCs into the cell type of the interest. The rationale behind this approach is to screen for various panel of drugs that specifically kill cells carrying oncogenic mutations. Since chemotherapy drugs have undesirable side effects,, cytoxicity drugs screening assays need to be developed that selectively target mainly cancer cells and have minimized side-effects. In one of the case report published by Moriguchi and Mandane, they have successfully generated patient-specific hepatoma-like cells (HLCs) derived from the iPSCs of the patient suffering from hepatocellular carcinoma (HCC) [22]. They later performed the in vitro anticancer drug sensitivity assay on HLCs using acyclic retinoid (ACR) plus tolrestat as an aldo-ketoreducatse family 1, member 10 (AKR1B10) inhibitor. As a result of the drug treatment, the patient cancer cells were eliminated six days later in vitro. Based on this drug sensitivity results, the patient was treated with ACR plus tolrestat therapy and his HCC was disappeared in three months [23]. This study provided the proof-of-concept for the development of drug treatment using the iPSCs technology.

\section{Can we reprogram human primary cancer cells? -the big paradox}

Similar to non-cancerous cells, many attempts has been made to reprogram human primary cancer cell lines to pluripotency. Despite all the efforts, it has proven that reprogramming primary human cancer cell lines is inefficient and hence called the 'paradox'. Although technical constraint is one of the potential reasons for failure, there is compelling evidence of biological hurdles as another barrier. Hochelinger et.al 2004 have shown that blastocytes cloned from RAS- induced melanpoma nuclei give rise to Embryonic Cell (EC) which can differentiate into malonocytes, Lymphocytes and fibroblasts. However this reprograming was not possible by nuclei of Lekemia, Lymohoma or breast cancer cells to produce EC cells [24]. Alternatively, cancer-specific genetic mutations, DNA damage, epigenetic modifications and oncogene-induced senescence also impose the additional hurdles in reprogramming but they do not represent an insurmountable one, a topic that has been reviewed in great detail elsewhere [25].

Despite all the hurdles, several researchers have published the generation of novel iPSCs from cancer cell lines. Carette et.al 2010 have demonstrated succesfully the generation and characterization of iPSCs derived from human chronic myeloid leukemia cells by transfecting 4 sets of transcriptional factors such as Oct4, SOX2, cMyc \& Klf4. Interestingly, it was observed that the parental cell line was strictly dependent on the BCR-ABL signaling, however, reprogrammed cells lost this dependency and became resistant to the BCR-ABL inhibitor imatinib. This finding thus indicated that the therapeutic agent imatinib targets cells in a specific epigenetic differentiated cell state and this may contribute to its inability to fully eradicate disease in chronic myeloid leukemia patients [26]. In another study published by Choi et.al 2011 have used EBV-immortalized B lymphocyte cell lines which represent an important source of genetic information from patients of various diseases including cancer. These EBV-B cells can be excellent resource for generation of diseases specific iPSCs \& can be used for various human diseases. Choi et al. have successfully reprogramed these EBV- B 
cells by using non-viral vectors and shown that the iPSCs generated by this method retained the inherited diseases properties [27]. Finally, the most interesting work on cancer cell reprogramming came from Hu's laboratory. Because of limited genetic abnormalities in hematopoietic cells in many blood diseases, several studies have demonstrated successful reprogramming of Cord Blood \& peripheral blood cells to generation of iPSCs cells and thus this is become a successful iPSC-based models for hematologic diseases. However, there are limitations of current reprogramming technologies include low efficiency, slow kinetics, transgene integration and residual expression. Hu et. al 2011 have overcome these limitations \& demonstrated the generation of iPSCs from BM \& $C B$ mononuclear cells which was free of transgene and vector sequences using non-integrating episomal vectors. The reprogramming was up to 100 times more efficient, occurs within 1-3 weeks faster as compared with the reprogramming of fibroblasts, and does not require isolation of progenitors or multiple rounds of transfection. They have also generated iPSCs from BM of a patient with chronic myeloid leukemia (CML) and showed a unique complex chromosomal translocation identified in marrow sample while displaying typical embryonic stem cell phenotype and pluripotent differentiation potential. This approach provides an opportunity to explore normal and diseased $\mathrm{CB}$ and BM samples without the limitations associated with virus-based methods [28] The scarcity in the report of reprogramming cancer cells has hampered the cancer research in dissecting all the additional factors imposing hurdles on successful reprogramming. Scientists working in oncology, stem cells and regenerative medicine should be persuaded to publish negative data which might provide specific clues to define these hurdles.

\section{Reversing the 'cancer state' to normal through epigenetic reprogramming}

A corollary to the reprogramming of cancer cells is that if they can be reversed to pluripotent state, it would suggest that the chromatin remodeling of oncogenes and tumor suppressor genes might results in reversing the 'cancer state'. However, it is also possible that chromatin modeling controlling the reprogramming process can also drives the 'cancer state' if subjected to aberrant regulation [29]. Thus, reprogramming, pluripotency and malignant transformation are connected processes that are dictated by epigenetics [28] For instance, in transformed lung fibroblast, epigenetic silencing of tumor suppressor gene p16 (CDKN2A) was reported to be a 'cancer driven' mechanism. However, reprogramming successfully restored the p16 gene expression and it was also associated with erasing of epigenetic lesions associated with cancer [23]. In another study published by Zhang and coworker, they have demonstrated that direct nuclear reprogramming of sarcoma cells not only abrogates their tumorigenicity but also reduce drug resistance. Further DNA methylation profiling on reprogrammed sarcoma cells indicated the permissive change in chromatic structure for methyl writers (c-Myc silencing) [30]. These findings suggest that the aggressiveness of cancer reduced after reprogramming and hence can be used as a potential therapy for cancer.

However, there are other studies which showed totally contradicting results on the oncogenic state of cancer cells after reprogramming. Exogenous expression of Oct4 in human primary breast cells results in transformation of cells with overexpressed telomerase and down-regulated p16. Further injection of these transformed cells in nude mice generated breast carcinomas with metastatic potential [31]. In another recent study, co-expression of both Oct4/Nanog enhanced malignancy in lung adenocarcinoma and induces epithelial-mesenchymal transition (EMT). Thus, both studies independently established the notion that these pluripotency genes if expressed aberrantly could become oncogenic driver imparting self-renewal capability to cancer cells - [32]. Therefore, before bringing reprograming of cancer cells by pluripotency genes as a one of the cancer therapy from bench to bedside, further investigation is still required regarding the optimum levels of reprogramming factors that should be expressed in the cancer cells in order to reverse the malignant phenotype. Nevertheless, the future is still looking bright for cancer cell reprogramming as a therapy due to the recent groundbreaking discovery by Mayo Clinic on reversing cancer cells back to normal through epigenetic remodeling [33]. In this study, Kourtidis et.al 2015 have highlighted the roles of E-cadherin and p120 catenin (p120) in exerting pro-tumorigenic activities of these proteins by balancing epithelial homeostasis in normal cells. They have resolved this hypothesis by identifying two spatially and functionally distinct junctional complexes in normal epithelial cells. They have straightened out the complicated roles of E-cadherin and p120 in the context of distinct junctional complexes, separating their functions. In addition, they have identified PLEKHA7 as a specific marker of zonula adherens (ZA) that facilitates suppression of growth of transformed cells. Finally, they discovered that an interaction of the ZA with the microprocessor complex regulates a set of miRNAs to suppress cellular transformation and maintain the normal epithelial phenotype [33].

\section{IPSCs in cancer immunotherapy}

Immunotherapy is the holy grail for cancer treatment and it involves generation of tumor specific-immune cells which on adoptive transfer elicit cytotoxic response against tumor. It has already been applied in clinical settings but due to the shorter life span of activated 
cytotoxic $\mathrm{T}$ lymphocytes produced by conventional method, the effect is not substantial to cure patient [34]. To address this issue, the iPSCs technology could provide the platform to clone and expand tumor-specific $\mathrm{T}$ cells. Lei and coworkers have demonstrated for the first time that iPSCs could differentiate into $\mathrm{T}$ lymphocytes when co-cultured with OP9 cells. They have further reported that iPSCs-derived $\mathrm{T}$ cells could be successfully utilized for adoptive immunotherapy using Rag-deficient mice model - [35]. Another interesting study by Japanese researchers has provided an approach to generate and expand functional tumor antigen-specific $\mathrm{CD} 8^{+} \mathrm{T}$ cells. They have induced MART-1 antigen specific $\mathrm{T}$ cells into iPSCs and successfully generated large pool of MART-1 specific CD8+ T cells. The ex vivo generated $\mathrm{T}$ lymphocytes were functionally active and produced anti-tumor compound interferon- $\gamma$ when stimulated with MART-1 antigen [36]. The next critical step is to see whether these regenerated $\mathrm{T}$ cells can selectively kill tumor cells in vitro and in vivo. In addition, such studies should be conducted with discretion since one of the reports has shown that iPSCs derived from various cell types exhibit different gene expression profile and has an influence on the differentiation potential. However, these differences were weakened by continuous passaging of iPSCs cells [37].

Natural killer cells, another player of innate immune system also play an important role in generating antitumor response by secreting Th1 cytokines [38]. However, the only hurdle in the application of NK cells for immunotherapy is to get the sufficient number of cells which can be infused in patient. Woll et al.for the first time developed a method to differentiate human ES cells into functional NK cells in vitro [39]. Subsequently, using the similar culture system, NK cells were also successfully differentiated from human iPS cells. Importantly, these iPSCs-derived NK cells had the potential to actively suppress human tumor cells and they produced high levels of interferon- $\gamma$ [40]. In a recent study, it has been shown that NKT cells could also be derived from iPS cells. These cells play an important role in cancer immune surveillance as they share the properties of both NK and T cells [41].

Dendritic cells (DCs) are the most potent antigenpresenting cells and contribute strongly towards regulating the immune system by constitutively synthesizing high levels of MHC Class I/Class II molecules. For decades, DCs have been used to induce robust therapeutic immune modulation in a highly effective manner [42] Loading of DCs with tumor-specific antigens followed by reinfusion into the recipient organisms generated promising results both in mice [43] as well as in human trials [44]. The other advantages of using DCs is they can be genetically manipulated easily using viral gene delivery vectors, have shorter life-span and they don't proliferate indefinitely as in the case of gene modified $\mathrm{T}$ cells which sometimes result in lymphoma [45]. Despite the promising results, isolation and in vitro propagation of DCs still represents the most challenging task which also increases the overall costs. This therapeutic limitation of DCs can be overcome by using iPSCs-derived DCs and hence represents the renewable source to broaden the immunotherapeutic applications [46]. Silk et al. have successfully generated $\mathrm{CD} 141^{+} \mathrm{XCR} 1^{+} \mathrm{DCs}$ from iPSCs using combination of stem cell factor (SCF), granulocyte macrophage-colony stimulating factor (GM-CSF), bone morphogenetic protein-4 (BMP4) and vascular endothelial growth factor (VEGF) without the usage of animal products. These iPSCs-derived DCs efficiently processed the recombinant TAA, Melan A antigens and cross-presented to naïve $\mathrm{CD}^{+} \mathrm{T}$ cells resulting in immune response [47]. Thus, considering all the immense potential of iPSCs in the field of immunotherapy, we are definitely not far from the days when we can look back on chemotherapy and radiotherapy as barbaric way of treating cancer.

\section{Gene correction in iPSCs and autologous transplantation: precision medicine}

Molecular scissors such as zinc finger nucleases (ZFN), transcription activator like-effector nuclease (TALEN) and clustered regularly interspaced short palindromic repeats (CRISPR) have emerged as the powerful gene editing tools to conduct precise-genome editing including the correction of disease-associated mutations [48-50]. Zinc finger nucleases (ZFNs) are synthetic DNA-binding proteins which facilitate genome editing by creating a double-stranded break by cleaving domain of the FokI restriction endonuclease in DNA at a user-specified location. This double-stranded break stimulates the cell's natural DNA-repair processes and thus by using well-established protocols, these cellular processes can be harnessed to generate precisely targeted in vitro or in vivo genomic edits with targeted gene deletions (Knockouts), integrations, or modifications. ZFNs are broadly applicable and accessible molecular tools for performing targeted genetic alterations [48]. Whereas, Transcription Activator-like Effector Nucleases (TALENs) works on the same principle as ZFNs. TALENs are fusions of transcription activator-like (TAL) proteins and a FokI nuclease. TAL proteins are composed of 33-34 amino acid repeating motifs with two variable positions that have a strong recognition for specific nucleotides. By assembling arrays of these TALs and fusing them to a FokI nuclease, specific cutting of the genome can be achieved. When two TALENs bind and meet, the FokI domains induce a double-strand break which can inactivate a gene, or can be used to insert DNA of interest. TALENs are more 
specific than ZFNs, which don't have the cross-reactivity problem that faced by ZFN researchers [49]. The third newly developed gene editing technology is the Clustered, Regularly Interspaced, Short Palindromic Repeat (CRISPR) technology which generates RNA-guided nucleases, such as Cas9, with customizable specificities. Genome editing mediated by these nucleases has been used to modify endogenous genes in a wide variety of cell types. These systems will influence to perform targeted \& highly efficient alterations of genome sequence and will certainly alter biological research program towards development of novel molecular therapeutics for human disease [50]. But how these genome editing tools could be utilized in the field of iPSCs in context to treat cancer? Most of the cancers are caused due to a mutation in a specific gene; the mutated gene of patient cells can be corrected through genome editing tools. The corrected cells of patient can be converted into iPSCs and differentiate them into specific-lineage of cells which could be used further in autologous transplantation approach as a therapy in future [51]. For instance, mammary gland is the primary target of breast cancer caused by the mutations in the BRCA1/ BRCA2 genes [52] Treatment for breast cancer usually involves a combination of radiotherapy and chemotherapy which often results in damaging the mammary glands. The only way to restore the function of mammary gland is simply by regenerating the damaged gland. Li et al., have successfully developed iPSCs from mouse mammary epithelial cells (ME-iPSCs) and re-differentiated them back into mammary epithelial cells (D-ME-iPSCs). Further transplantation of these D-ME-iPSCs into the fat pads of the mammary glands of nude mice result in the generation of mammary tree-like structures in vivo [53] Thus, this study envisions the use of iPSCs-derived tissue which could be used in parallel with gene editing tools to generate genetically corrected BRCA1/BRCA2 mammary cells. Besides, this gene editing platform has been successfully utilized to correct gene defect in iPSCs-derived from severe combined immunodeficiency (SCID) [53] and fanconi aneamia patient (hematological diseases) [54].

However, there are current limitations to the use of gene editing tools to precisely delete or modify cancer genes in patient as a therapy. The efficiency of gene targeting in iPSCs using homologous recombination is very low [55]. and the use of viral vectors for gene modifications causes insertional mutagenesis which represents the most significant hurdle in clinical translation [10]. Despite the fact that bone marrow transplantation is a routine medical procedure, there is still no sign of clinical translation on gene corrected iPSCs. The other missing link seems to be the development of novel protocol for the generation of iPSCs-derived transplantable cells which could result in successful engraftment in the host. A deeper understanding in the biology of organs development, pre-clinical studies in various animal models and the development of viral free high efficient gene targeting technology are needed to address all the hurdles.

\section{Conclusions}

Induced pluripotent stem cells have ushered a new era in the field of cancer biology and are the most promising technology to conduit between the bench and bedside. Some scientists have called it as the 'holy grail' of $21^{\text {st }}$ century. Since it is possible to develop patient specific iPSCs from somatic tissues, this contributes in modeling diseases, drug development and autologous stem cells therapy. In the field of cancer, iPSCs has provided a double-edge sword that enable scientist not only to unravel the long mystery of epigenetic events contributing to cancer but also a renewable resource to develop plethora of immune cells for immunotherapy. By using the recent gene editing tools, it is also possible to correct the genetic defect in patient-specific iPSCs which could be used in autologous transplantation. The ample amount of knowledge that can be generated from this technology will leads to better drug screening that will have more targeted effect and less toxicity. Thus, the iPSCs technology will definitely accelerate the field of scientific research in finding new treatment for treating cancer and other disorders.

\section{Abbreviations}

iPSCs: Induced pluripotent stem cells; Sox2: Sex determining region Y; Klf4: Kruppel-like factor 4; c-Myc: Myelocytometosis; hESCs: Human embryonic stem cells; BAF: Brg1/Brm associated factor; BCR-ABL: Breakpoint cluster region-abelson murine leukemia; PDAC: Pancreatic ductal adenocarcinoma; LFS: Li-Fraumeni syndrome; HLCs: Hepatoma-like cells; HCC: Hepatocellular carcinoma; PanIN: Pancreatic intraepithelial neoplasia; HNF4a: Hepatocyte nuclear factor 4; ACR: Acyclic retinoid; AKR1B10: Aldo-ketoreductase family member 10; CDKN2A: Cyclin-dependent kinase inhibitor 2A; EMT: Epithelialmesenchymal transition; MART-1: Melanoma antigen recognized by T cells 1; NK: Natural killer cells; DC: Dendritic cells; Th1:T helper 1; BRCA: Breast cancer; Oct4: Octamer-binding transcription factor 4

\section{Acknowledgements}

This work was supported by intramural funding from Jaslok Hospital \& Research Centre, Mumbai, India. We are thankful to the management of Jaslok Hospital for providing the stem cells facility to carry out stem cell research at this hospital.

\section{Funding}

Currently, we don't have any funding.

Availability of data and materials

It is Review Article.

Authors' contributions

Both authors read and approved the final amnucript.

Competing interests

The authors declare that they have no competing interests.

Consent for publication

Not applicable as it is Review article. 


\section{Ethics approval and consent to participate}

Not applicable as it is Review article.

\section{Received: 20 August 2016 Accepted: 22 February 2017 Published online: 06 March 2017}

\section{References}

1. Gurdon JB, Laskey RA, Reeves OR. The developmental capacity of nuclei transplanted from keratinized skin cells of adult frogs. J Embryol Exp Morphol. 1975;34:93-112.

2. Wilmut I, Schnieke AE, McWhir J, Kind AJ, Campbell KH. Viable offspring derived from fetal and adult mammalian cells. Nature. 1997;385:810-3.

3. Thomson JA, Eldor JI, Shapiro SS, Waknitz MA, et al. Embryonic Stem Cell Lines Derived from Human Blastocysts. Science. 1998;282:1145-7.

4. Takahashi K, Yamanaka S. Induction of Pluripotent Stem Cells from Mouse Embryonic and Adult Fibroblast Cultures by Defined Factors. Cell. 2006;126:663-76.

5. Yu J, Vodyanik MA, Smuga-Otto K, Antosiewicz-Bourget J, Frane JL, Tian S, Nie J, Jonsdottir GA, Ruotti V, Stewart R, Slukvin II, Thomson JA. Induced pluripotent stem cell lines derived from human somatic cells. Science. 2007;318:1917-20

6. Yamanaka S, Takahashi K, Tanabe K, Ohnuki M, Narita M, Ichisaka T, Tomoda K. Induction of pluripotent stem cells from adult human fibroblasts by defined factors. Cell. 2007:131:861-72.

7. Raya A, Rodríguez-Pizà I, Guenechea G, Vassena R, Navarro S, Barrero MJ, Consiglio A, Castellà M, Río P, Sleep E, González F, Tiscornia G, Garreta E, Aasen T, Veiga A, Verma IM, Surrallés J, Bueren J, Izpisúa Belmonte JC. Disease-corrected haematopoietic progenitors from Fanconi anaemia induced pluripotent stem cells. Nature. 2009;460:53-9.

8. Maehr R, Chen S, Snitow M, Ludwig T, Yagasaki L, Goland R, Leibel RL, Melton DA. metabolic. Proc Natl Acad Sci U S A. 2009;106:15768-73.

9. Rashid ST, Corbineau S, Hannan N, Marciniak SJ, Miranda E, Alexander G, Huang-doran I, Griffin J, Ahrlund-richter L, Skepper J, Semple R, Weber A, Lomas DA, Vallier L. Modeling inherited metabolic disorders of the liver using human induced pluripotent stem cells. J Clin Invest. 2010;120:3127-36.

10. Baum C. Insertional mutagenesis in gene therapy and stem cell biology. Curr Opin Hematol. 2007;14:337-42.

11. Hanna J, Saha K, Pando B, van Zon J, Lengner CJ, Creyghton MP, van Oudenaarden A, Jaenisch R. Direct cell reprogramming is a stochastic process amenable to acceleration. Nature. 2009;462:595-601.

12. Ban H, Nishishita N, Fusaki N, Tabata T, Saeki K, Shikamura M, Takada N, Inoue M, Hasegawa M, Kawamata S, Nishikawa S-I. Efficient generation of transgene-free human induced pluripotent stem cells (iPSCS) by temperaturesensitive Sendai virus vectors. Proc Natl Acad Sci U S A. 2011;108:14234-9.

13. Stadtfeld M, Nagaya M, Utikal J, Weir G, Hochedlinger K. Induced pluripotent stem cells generated without viral integration. Science. 2008;322:945-9.

14. Okita K, Matsumura Y, Sato Y, Okada A, Morizane A, Okamoto S, Hong H, Nakagawa M, Tanabe K, Tezuka K, Shibata T, Kunisada T, Takahashi M, Takahashi J, Saji H, Yamanaka S. A more efficient method to generate integration-free human iPS cells. Nat Methods. 2011:8:409-12.

15. Warren L, Manos PD, Ahfeldt T, Loh Y, Li H, Daley Q, Brack AS, Collins JJ, Cowan C, Thorsten M. Highly efficient reprogramming to pluripotency and directed differentiation of human cells with synthetic modified mRNA. Cell Stem Cell. 2010:7:618-30

16. Huangfu D, Maehr R, Guo W, Eijkelenboom A, Snitow M, Chen AE, Melton DA. Induction of pluripotent stem cells by defined factors is greatly improved by small-molecule compounds. Nat Biotechnol. 2008;26:795-7.

17. Singhal N, Graumann J, Wu G, Araúzo-Bravo MJ, Han DW, Greber B, Gentile L, Mann M, Schöler HR. Chromatin-remodeling components of the baf complex facilitate reprogramming. Cell. 2010;141:943-55.

18. Kleger A, Mahaddalkar PU, Katz SF, Lechel A, Joo JY, Loya K, Lin Q, Hartmann D, Liebau S, Kraus JM, Cantz T, Kestler HA, Zaehres H, Schler H, Rudolph KL. Increased reprogramming capacity of mouse liver progenitor cells, compared with differentiated liver cells, requires the BAF complex. Gastroenterology. 2012;142:907-17.

19. Hochedlinger K, Blelloch R, Brennan C, Yamada Y, Kim M, Chin L, Jaenisch R. Reprogramming of a melanoma genome by nuclear transplantation. Genes Dev. 2004;18:1875-85.

20. Ramos-Mejia V, Fraga MF, Menendez P. iPSCs from cancer cells: challenges and opportunities. Trends Mol Med. 2012;18:245-7.
21. Carette JE, Pruszak J, Varadarajan M, Blomen VA, Gokhale S, Camargo FD, Wernig M, Jaenisch R, Brummelkamp TR. Generation of iPSCs from cultured human malignant cells. Blood. 2010;115:4039-42.

22. Choi SM, Liu H, Chaudhari P, Kim Y, Cheng L, Feng J, Sharkis S, Ye Z, Jang YY. Reprogramming of EBV-immortalized B-lymphocyte cell lines into induced pluripotent Stem cells. Blood. 2011:118:1801-5.

23. Hu K, Yu J, Suknuntha K, Tian S, Montgomery K, Choi KD, Stewart R, Thomson JA, Slukvin II. Efficient generation of transgene-free induced pluripotent stem cells from normal and neoplastic bone marrow and cord blood mononuclear cells. Blood. 2011;117:e109-119.

24. Banito A, Gil J. Induced pluripotent stem cells and senescence: learning the biology to improve the technology. EMBO Rep. 2010;11:353-9.

25. Kim J, Hoffman JP, Alpaugh RK, Rhimm AD, Reichert M, Stanger BZ, Furth EE, Sepulveda AR, Yuan CX, Won KJ, Donahue G, Sands J, Gumbs AA, Zaret KS. An iPSC Line from Human Pancreatic Ductal Adenocarcinoma Undergoes Early to Invasive Stages of Pancreatic Cancer Progression. Cell Rep. 2013;3:2088-99.

26. Lee DF, Su J, Kim HS, Chang B, Papatsenko D, Zhao R, Yuan Y, Gingold J, Xia W, Darr H, Mirzayans R, Hung MC, Schaniel C, Lemischka IR. Modeling familial cancer with induced pluripotent stem cells. Cell. 2015;161:240-54.

27. Moriguchi H, Chung R, Sato C. An Identification of Novel Therapy for Human Hepatocellular Carcinoma by Using Human Induced Pluripotent Stem Cells. Hepatol. 2010;51:1090-1.

28. Moriguchi $\mathrm{H}$, Madson J. The reprogramming therapy for a patient with advanced hepatocellular carcinoma by using human-induced pluripotent stem (iPS) cells technology. BMJ Case Rep. 2013;2:2013. doi:10.1136/bcr-2013-008950.

29. Onder TT, Kara N, Cherry A, Sinha AU, Zhu N, Bernt KM, Cahan P, Marcarci BO, Unternaehrer J, Gupta PB, Lander ES, Armstrong SA, Daley GQ. Chromatinmodifying enzymes as modulators of reprogramming. Nature. 2012;483:598-602.

30. Zhang X, Cruz FD, Terry M, Remotti F, Matushansky I. Terminal differentiation and loss of tumorigenicity of human cancers via pluripotency-based reprogramming. Oncogene. 2013;32:2249-60. doi:10.1038/onc.2012.237.

31. Beltran AS, Rivenbark AG, Richardson BT, Yuan X, Quian H, Hunt JP, Zimmerman E, Graves LM, Blancafort P. Generation of tumor-initiating cells by exogenous delivery of OCT4 transcription factor. Breast Cancer Res. 2011;13:R94

32. Chiou SH, Wang ML, Chou YT, Chen CJ, Hong CF, Hsieh WJ, Chang HT, Chen YS, Lin TW, Hsu HS, Wu CW. Coexpression of Oct4 and Nanog enhances malignancy in lung adenocarcinoma by inducing cancer stem cell-like properties and epithelial-mesenchymal transdifferentiation. Cancer Res. 2010;70:10433-44.

33. Kourtidis A, Ngok SP, Pulimeno P, Feathers RW, Carpio LR, Baker TR, Carr JM, Yan IK, Borges S, Perez EA, Storz P, Copland JA, Patel T, Thompson EA, Citi S, Anastasiadis PZ. Distinct E-cadherin-based complexes regulate cell behaviour through miRNA processing or Src and p120 catenin activity. Nat Cell Biol. 2015:17:1145-57.

34. Mescher MF, Popescu FE, Gerner M, Hammerbeck CD, Curtsinger JM. Activation-induced non-responsiveness (anergy) limits CD8 T cell responses to tumors. Semin Cancer Biol. 2007;17(4):299-308

35. Lei $F$, Haque R, Weiler L, Vrana KE, Song J. T lineage differentiation from induced pluripotent stem cells. Cell Immunol. 2009;260:1-5.

36. Vizcardo R, Masuda K, Yamada D, Ikawa T, Shimizu K, Fujii SI, Koseki H, Kawamoto H. Regeneration of human tumor antigen-specific $\mathrm{T}$ cells from iPSCs derived from mature CD8+ T cells. Cell Stem Cell. 2013:12:31-6.

37. Polo JM, Liu S, Figueroa ME, Kulalert W, Eminli S, Tan KY, Apostolou E, Stadtfeld M, Li Y, Shioda T, Natesan S, Wagers AJ, Melnick A, Evans T, Hochedlinger K. Cell type of origin influences the molecular and functional properties of mouse induced pluripotent stem cells. Nat Biotechnol. 2010;28:848-55.

38. Milani V, Stangl S, Issels R, Gehrmann M, Wagner B, Hube K, Mayr D, Hiddemann W, Molls M, Multhoff G. Anti-tumor activity of patient-derived NK cells after cell-based immunotherapy - a case report. J Transl Med. 2009:7:50.

39. Woll PS, Martin CH, Miller JS, Kaufman DS. Human embryonic stem cell-derived NK cells acquire functional receptors and cytolytic activity. J Immunol. 2005; $175: 5095-103$

40. Knorr DA, Ni Z, Hermanson D, Hexum MK, Bendzick L, Cooper LJN, Lee DA, Kaufman DS. Clinical-scale derivation of natural killer cells from human pluripotent stem cells for cancer therapy. Stem Cells Transl Med. 2013;2:274-83.

41. Fujii S ichiro, Shimizu K, Okamoto Y, Kunii N, Nakayama T, Motohashi S, Taniquchi M: NKT cells as an ideal anti-tumor immunotherapeutic. Front. Immunol., 02 December 2013 | http://dx.doi.org/10.3389/fimmu.2013.00409 
42. de Andrade PB, Fraefel C. Novel immunotherapeutic approaches in targeting dendritic cells with virus vectors. Discov Med. 2015;20:111-9.

43. Badovinac V, Messingham K, Jabbari A, Haring J, Harty J. Accelerated CD8+ T-cell memory and prime-boost response after dendritic-cell vaccination. Nat Med. 2005;11:748-56.

44. Dillman RO, Cornforth AN, Depriest C, McClay EF, Amatruda T, de Leon C, Ellis RE, Mayorga C, Carbonell D, Cubellis JM. Tumor stem cell antigens as consolidative active specific immunotherapy: a randomized phase II trial of dendritic cells versus tumor cells in patients with metastatic melanoma. J Immunother. 2012;35:641-9.

45. Merad M, Sathe P, Helft J, Miller J, Mortha A. The dendritic cell lineage: ontogeny and function of dendritic cells and their subsets in the steady state and the inflamed setting. Annu Rev Immunol. 2013;31:563-604.

46. Silk KM, Silk JD, Ichiryu N, Davies TJ, Nolan KF, Leishman AJ, Carpenter L, Watt SM, Cerundolo V, Fairchild PJ. Cross-presentation of tumour antigens by human induced pluripotent stem cell-derived CD141 + XCR1+ dendritic cells. Gene Ther. 2012;19:1035-40.

47. Leishman A, Fairchild PJ. Differentiation of Dendritic Cells from Human Induced Pluripotent Stem Cells. Stem Cells and Cancer Stem Cells. 2013;12:29-37.

48. Urnov FD, Rebar EJ, Holmes MC, Zhang HS, Gregory PD. Genome editing with engineered zinc finger nucleases. Nat Rev Genet. 2010;11:636-46.

49. Deng D, Yan C, Wu J, Pan X, Yan N. Revisiting the TALE repeat. Protein Cell. 2014:5:297-306.

50. Sander JD, Joung JK. CRISPR-Cas systems for editing, regulating and targeting genomes. Nat Biotechnol. 2014;32:347-55.

51. Jiang Z, Han Y, Cao X. Induced pluripotent stem cell (iPSCs) and their application in immunotherapy. Cell Mol Immunol. 2014;11:17-24.

52. Brody LC, Biesecker BB. Breast cancer susceptibility genes. BRCA1 and BRCA2. Medicine (Baltimore). 1998;77:208-26.

53. Menon T, Firth AL, Scripture-Adams DD, Galic Z, et al. Lymphoid regeneration from gene-corrected SCID-X1 subject-derived iPSCs. Cell Stem Cell. 2015;16(4):367-72.

54. Liu G-H, Suzuki K, Li M, Qu J, Montserrat N, Tarantino C, Gu Y, Yi F, Xu X, Zhang W, Ruiz S, Plongthongkum N, Zhang K, Masuda S, Nivet E, Tsunekawa Y, Soligalla RD, Goebl A, Aizawa E, Kim NY, Kim J, Dubova I, Li Y, Ren R, Benner C, Del Sol A, Bueren J, Trujillo JP, Surralles J, Cappelli E, et al. Modelling Fanconi anemia pathogenesis and therapeutics using integration-free patient-derived iPSCs. Nat Commun. 2014;5:4330.

55. Sánchez-Rivera FJ, Jacks T. Applications of the CRISPR-Cas9 system in cancer biology. Nat Rev Cancer. 2015;15:387-95.

\section{Submit your next manuscript to BioMed Central and we will help you at every step:}

- We accept pre-submission inquiries

- Our selector tool helps you to find the most relevant journal

- We provide round the clock customer support

- Convenient online submission

- Thorough peer review

- Inclusion in PubMed and all major indexing services

- Maximum visibility for your research

Submit your manuscript at www.biomedcentral.com/submit

) Biomed Central 